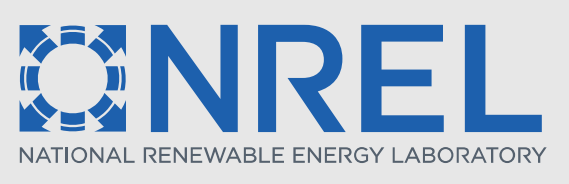

\title{
Catalytic Upgrading of Sugars to Hydrocarbons Technology Pathway
}

Mary Biddy

National Renewable Energy Laboratory

Susanne Jones

Pacific Northwest National Laboratory

NREL is a national laboratory of the U.S. Department of Energy, Office of Energy Efficiency \& Renewable Energy, operated by the Alliance for Sustainable Energy, LLC, under contract DE-AC36-08G028308.

Pacific Northwest National Laboratory is operated by Battelle for the United States Department of Energy under contract DE-AC05-76RL01830.

\section{Technical Report}

NREL/TP-5100-58055

PNNL-22319

March 2013

Prepared for the U.S. Department of Energy Bioenergy Technologies Office 


\section{Catalytic Upgrading of Sugars to Hydrocarbons Technology Pathway}

Mary Biddy

National Renewable Energy Laboratory

Susanne Jones

Pacific Northwest National Laboratory

NREL is a national laboratory of the U.S. Department of Energy, Office of Energy Efficiency \& Renewable Energy, operated by the Alliance for Sustainable Energy, LLC, under contract DE-AC36-08GO28308.

Pacific Northwest National Laboratory is operated by Battelle for the United States Department of Energy under contract DE-AC05-76RL01830.

Technical Report

NREL/TP-5100-58055

PNNL-22319

March 2013

Prepared for the U.S. Department of Energy Bioenergy Technologies Office

National Renewable Energy Laboratory 15013 Denver West Parkway Golden, Colorado 80401 303-275-3000 • www.nrel.gov
Pacific Northwest National Laboratory P.O. Box 999

Richland, WA 99352

1-888-375-7665 • www.pnl.gov 


\section{NOTICE}

This report was prepared as an account of work sponsored by an agency of the United States government. Neither the United States government nor any agency thereof, nor the Alliance for Sustainable Energy, LLC, nor Battelle Memorial Institute, nor any of their employees, makes any warranty, express or implied, or assumes any legal liability or responsibility for the accuracy, completeness, or usefulness of any information, apparatus, product, or process disclosed, or represents that its use would not infringe privately owned rights. Reference herein to any specific commercial product, process, or service by trade name, trademark, manufacturer, or otherwise does not necessarily constitute or imply its endorsement, recommendation, or favoring by the United States government or any agency thereof. The views and opinions of authors expressed herein do not necessarily state or reflect those of the United States government or any agency thereof, or the Alliance for Sustainable Energy, LLC, or Battelle Memorial Institute.

Available electronically at http://www.osti.gov/bridge

Available for a processing fee to U.S. Department of Energy and its contractors, in paper, from:

U.S. Department of Energy

Office of Scientific and Technical Information

P.O. Box 62

Oak Ridge, TN 37831-0062

phone: 865.576 .8401

fax: 865.576.5728

email: mailto:reports@adonis.osti.gov

Available for sale to the public, in paper, from:

U.S. Department of Commerce

National Technical Information Service

5285 Port Royal Road

Springfield, VA 22161

phone: 800.553 .6847

fax: 703.605.6900

email: orders@ntis.fedworld.gov

online ordering: http://www.ntis.gov/help/ordermethods.aspx

Printed on paper containing at least $50 \%$ wastepaper, including $10 \%$ post consumer waste. 


\section{Catalytic Upgrading of Sugars to Hydrocarbons}

\section{Developing Technology Pathway Cases to Understand the Cost of Converting Biomass to Hydrocarbon Fuels}

In support of the Bioenergy Technologies Office, the National Renewable Energy Laboratory (NREL) and the Pacific Northwest National Laboratory (PNNL) are undertaking studies of biomass conversion technologies to hydrocarbon fuels to identify barriers and target research toward reducing conversion costs.

Process designs and preliminary economic estimates for each of these pathway cases were developed using rigorous modeling tools (Aspen Plus and Chemcad). These analyses incorporated the best information available at the time of development, including data from recent pilot- and bench-scale demonstrations, collaborative industrial and academic partners, and published literature and patents. The economic results of these analyses are in the process of further refinement and will be published in FY13 and FY14 design reports. This report summarizes the preliminary technical data used for the models and identified data gaps.

This technology pathway case investigates the catalytic conversion of solubilized carbohydrate streams to hydrocarbon biofuels, utilizing data from recent efforts within the National Advanced Biofuels Consortium (NABC) in collaboration with Virent, Inc. Technical barriers and key research needs that should be pursued for the catalytic conversion of sugars pathway to be competitive with petroleum-derived gasoline-, diesel-, and jet-range hydrocarbon blendstocks have been identified.

\section{Process Block Diagram}

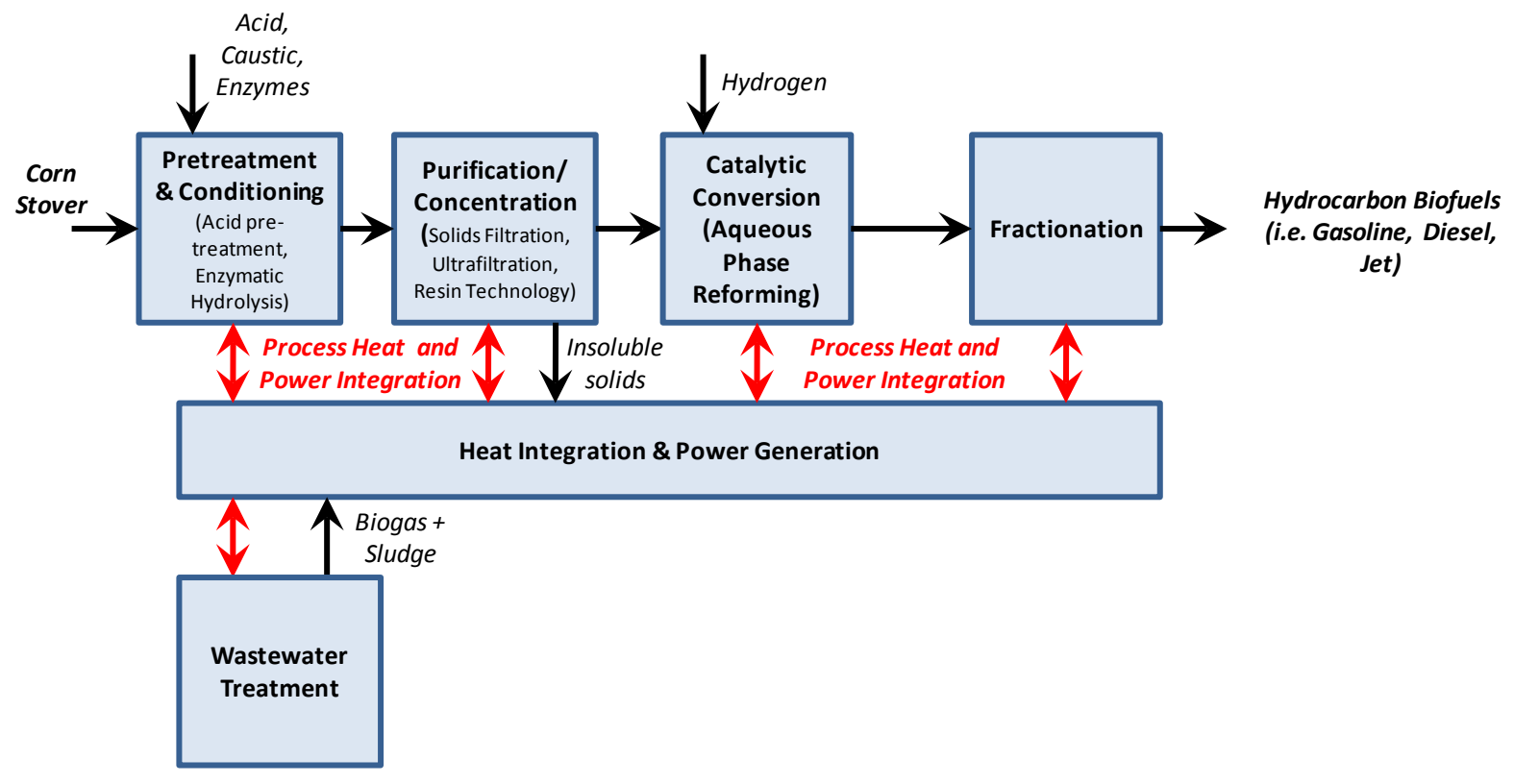




\section{Key Highlights}

- The catalytic upgrading of sugars to hydrocarbons pathway utilizes a catalytic conversion route for the production of hydrocarbon biofuels from a solubilized carbohydrate stream, leveraging prior experience in cellulosic sugar production.

- This pathway produces drop-in fuel blendstocks over a wide range of products that can be directly blended without further catalytic or chemical modification, including potential for production of biomass-derived chemicals, such as para-xylene for PET saturated polyester polymers.

- Catalytic conversion has the flexibility to utilize a wide range of biomass-derived deconstruction products that would be detrimental to microorganisms in fermentative conversion processes, including organic acids, furanics, and lignin deconstruction products.

- There is potential to maximize synergistic benefits with upstream sugar production and biomass deconstruction steps (pretreatment/enzymatic hydrolysis) and to explore new coproduct opportunities.

- Important research needs for this pathway include the production of hydrolysate streams tailored for catalytic upgrading, the design of catalysts with enhanced selectivities toward desired product slates, and the development of routes for lignin utilization.

\section{Process Design Details}

The process described here uses co-current dilute-acid pretreatment of lignocellulosic biomass (corn stover), followed by enzymatic hydrolysis (saccharification) of the remaining cellulose, followed by catalytic conversion of the resulting glucose, xylose, and other solubilized carbon components to hydrocarbon fuels in the gasoline, jet, and diesel fuel ranges. The process design also includes feedstock handling and storage, hydrolysate conditioning, product recovery, wastewater treatment, lignin combustion, product storage, and required utilities.

Feed handling and preparation: Corn stover, with a mean particle size of $<0.25$ inch, carbohydrate content of $59 \mathrm{wt} \%$, and moisture content of $<20 \mathrm{wt} \%$, is delivered at a rate of 2,000 dry metric tons per day. All costs associated with feed handling operations are included in the delivered feedstock cost values. From there, the biomass is conveyed to the pretreatment reactor. This area is identical to the 2011 biochemical ethanol design (Humbird et al. 2011).

Pretreatment and conditioning: The biomass is treated with dilute sulfuric acid catalyst (acid loading ranging from $0-3 \mathrm{wt} \%)$ at a high temperature $\left(130^{\circ}-220^{\circ} \mathrm{C}\right)$ for a short time $(2-30$ minutes) to liberate the hemicelluloses sugars and break down the biomass for enzymatic hydrolysis. The whole pretreated slurry is adjusted to $\mathrm{pH} \sim 5$ for enzymatic hydrolysis.

The current design utilizes biomass pretreatment processes proven effective and economically viable for cellulosic ethanol fermentation, which requires a hydrolysate stream primarily composed of monomeric sugars. Catalytic processes can convert a wider range of components derived from biomass in addition to monomeric sugars to hydrocarbon products, including oligomeric sugars, C5 and C6 sugars, and degradation products from the carbohydrate fraction, as well as lignin intermediates. This leads to potentially higher overall yields by utilizing a larger 
portion of the biomass feedstock. Future research efforts focused on developing tailored hydrolysate streams for catalytic upgrading can lead to improving the overall process yields. Targeting oligomeric rather than monomeric sugars opens new opportunities for lower severity and potentially lower cost pretreatment routes, such as processes that reduce or even eliminate chemical usage. Potential benefits for these alternative pretreatment options include reducing the cost of the pretreatment reactor (due to cheaper materials of construction), lowering the amount of neutralizing chemicals resulting in lower operating costs, and lessening the hydrolysate purification/cleanup requirements.

Enzymatic hydrolysis: Enzymatic hydrolysis is performed in a series of batch parallel bioreactors using purchased cellulase enzyme at loadings of $\sim 20 \mathrm{mg}$ protein $/ \mathrm{g}$ cellulose.

The current deconstruction process is based on designs proven effective for the fermentative production of ethanol that target monomeric sugar utilization. Optimization of deconstruction strategies for catalytic processes, which utilize a wide range of biomass-derived intermediates for fuel production, is an important factor in the overall process economics. Because the deconstruction processes determine the product slate of biomass-derived intermediates and the potential introduction of contaminants, poisons, and fouling agents, opportunities exist to improve deconstruction routes and lower the cost of downstream processing steps. For example, exploring alternative hydrolysis concepts, such as partial or complete chemical hydrolysis to solubilize cellulose, that require lower enzyme dosages could lead to reductions in the hydrolysate purification processes and costs while still maximizing biomass intermediates available for catalytic conversion. Alternatively, changes in the upstream process could also involve development of enzyme preparations that are effective at generating soluble oligomers without going all the way to monomeric sugars to further lower cost and improve process efficiencies.

Purification and concentration: The hydrolysate slurry is conditioned for further downstream processing requirements of the catalytic upgrading processes.

Insoluble solids, resulting from unreacted or recondensed biomass components, are problematic as they can build up in a fixed bed reactor system and cause high pressure drop. Hydrolysate slurries have been reported to have as much as 30\% insoluble solids by weight. Removal of solids by centrifugation or filtration methods is possible (NABC 2013).

Proteins and inorganic compounds in hydrolysates from the deconstruction process are problematic for catalytic processing, as they impact materials of construction (e.g., chloride and fluoride), accumulate in heat exchangers (e.g., silica) and contribute to catalyst poisoning (e.g., sulfur). Removal of these contaminants is achievable utilizing known technologies, including ion exchange methods used for removing impurities in the sugar refining industry. However, as Virent has recently reported, based on laboratory tests the high amount of impurities in hydrolysates require frequent resin regeneration, which can greatly impact the overall process economics (NABC 2013). Alternative biomass pre-processing methods may also help to reduce the amount of contaminants introduced into the process and lower purification costs.

The hydrolysate is further dewatered to increase the concentration of sugars in the highly dilute hydrolysate stream (typical range of sugar concentration is $10-15 \mathrm{wt} \%$ ). This excess water, 
which is unreactive, results in higher heating requirements and larger process equipment. A vacuum evaporator is utilized to increase sugar concentrations while minimizing sugar degradation. During this process, a small amount of highly volatile deconstruction products are removed with the water, but the bulk of the deconstruction material and all of the sugars are retained in the concentrated hydrolysate syrup (NABC 2013).

Understanding the design trade-offs and demonstrating the efficiencies of the separation process options, including details of carbon losses and capital and operating costs, will be key for improving the overall economics.

Conversion: The purified hydrolysate slurry is sent to the catalytic conversion process. The first step in the conversion is the aqueous phase reforming (APR) process, which takes the wide range of solubilized carbohydrate stream and utilizes heterogeneous catalysis to reduce the oxygen content of the feedstock. The reactions in the APR step include reforming to generate hydrogen, dehydrogenation of alcohols/hydrogenation of carbonyls, deoxygenation reactions, hydrogenolysis, and cyclization. This process is operated at $175^{\circ}-300^{\circ} \mathrm{C}, 145-1,300 \mathrm{psi}$. The APR reactor effluent is sent to the acid condensation reactor, where conversion over a tailored ZSM-5 catalyst results in a gasoline-range blendstock (NABC 2011). This process produces hydrocarbon "drop-in" fuels. The modeling data and design are consistent with current runs being performed by Virent in the NABC using NREL-produced corn stover hydrolysate.

Fractionation: The product of the catalytic conversion process is sent to fractionation where it is separated to various hydrocarbon blendstocks.

Wastewater treatment: Plant wastewater streams are treated by anaerobic and aerobic digestion. The methane-rich biogas from anaerobic digestion is sent to the combustor, where sludge from the digesters is also burned. The treated water is suitable for recycling and is returned to the process.

Storage: This area provides bulk storage for chemicals used and products produced in the process.

Combustor, boiler, and turbogenerator: The solids from hydrolysate purification and wastewater treatment and the biogas from anaerobic digestion are combusted to produce highpressure steam for electricity production and process heat. The boiler produces excess steam that is converted to electricity for use in the plant and for sale to the grid. The area is identical to the 2011 biochemical ethanol design (Humbird et al. 2011).

Utilities: This area includes a cooling water system, chilled water system, process water manifold, and power systems.

\section{Data Gaps, Uncertainties, and Research Needs}

The goal of this pathway, similar to the other process pathways, is to reach a minimum fuel selling price of $\$ 3 /$ gallon of gasoline equivalent (in 2011 U.S. dollars). To reach this targeted product price, the key bottlenecks, uncertainties, and areas for further development are summarized as follows: 
- Optimize upstream biomass deconstruction processes for downstream upgrading. Catalytic conversion routes allow for more flexibility in the hydrolysate composition that can be utilized for fuels production. Unlike biological routes, which require primarily monomeric sugars for fuel production, catalytic routes can utilize oligomeric species, carbohydrate degradation products, and even lignin intermediates. To help reduce the overall conversion costs and maximize biomass carbon utilization, future work is needed to develop opportunities to lower downstream upgrading costs by tailoring the biomass deconstruction processes for catalytic upgrading. This includes investigating alternative deconstruction routes that maximize the desirable slate of components and minimize the cost of hydrolysate purification and conditioning steps for catalytic upgrading.

Opportunities for biomass preprocessing to remove components (i.e., ash) should also be explored as a means to improve catalytic performance and minimize hydrolysate conditioning costs.

- Minimize cost of hydrolysate conditioning steps. Alternative, lower cost hydrolysate conditioning steps, including solid/liquid separations and improved purification process steps should be investigated.

- Maximize carbon selectivity towards desired fuel products. Catalysts could be designed to have increased selectivity to hydrocarbon fuel products and to minimize sideor by-product steps. An understanding of catalyst fundamentals is needed to design better catalysts and understand catalyst selectivity. Rational design and development of catalysts could be accomplished using a combination of computational and experimental techniques

- Improve catalyst lifetime and durability. Understanding catalyst deactivation mechanisms for dirty hydrolysate poisoning will be critical to improving catalyst lifetimes and minimizing processing costs. Using biomass-derived hydrolysates can help identify problematic components. Determining the impact of lignin deconstruction products on catalyst lifetimes as a function of deconstruction routes will improve process integration and carbon efficiency for fuel production. A better fundamental understanding of both chemical conversion and poisoning mechanisms may help to design better catalysts that are resistant to contaminants and poisons.

- Utilize lignin for hydrocarbon production. Catalytic processes are more tolerant to the introduction of a range of carbon species than biological systems are. For these catalytic processes, lignin utilization has great potential for improving total hydrocarbon product yields and increasing overall carbon efficiency for biomass conversion compared to pathways focused on carbohydrate carbon conversion alone. The key challenges for lignin usage are difficulty solubilizing the components and avoiding side reactions that form more recalcitrant compounds. Development and demonstration of a catalyst that can effectively convert lignin products without severe deactivation can significantly improve overall economic viability.

\section{Summary and Next Steps}

Similar to the other technology process pathways, the techno-economic analysis of catalytic conversion of corn stover to gasoline-, diesel-, and jet-range hydrocarbon blendstocks was performed to identify technology gaps, uncertainties, and research needed to achieve a targeted 
minimum fuel selling price of $\$ 3 /$ gallon of gasoline equivalent. A design case detailing this pathway will be developed in FY14.

\section{References}

"Catalysis of Lignocellulosic Sugars Process Strategy." NABC website. Golden, CO: National Advanced Biofuels Consortium. http://www.nabcprojects.org/catalytic sugar.html.

Held, A.; Rozmiarek, R.; Cortright, R. (2012). Personal communication with Mary Biddy, Adam Bratis, and Andy Aden. Madison, WI: Virent, Inc.

Humbird, D.; Davis, R.; Tao, L.; Kinchin, C.; Hsu, D.; Aden, A.; Schoen, P.; Lukas, J.; Olthof, B.; Worley, M.; Sexton, D.; Dudgeon, D. (2011). Process Design and Economics for Biochemical Conversion of Lignocellulosic Biomass to Ethanol: Dilute-Acid Pretreatment and Enzymatic Hydrolysis of Corn Stover. NREL/TP-5100-47764. Golden, CO: National Renewable Energy Laboratory. http://www.nrel.gov/biomass/pdfs/47764.pdf.

NABC. (January 1, 2013). "Hydrolysate Conditioning in the Catalysis of Lignocellulosic Sugars Strategy.” NABC Highlight. Golden, CO: National Advanced Biofuels Consortium. http://www.nabcprojects.org/pdfs/hydrolysate conditioning cls 010113.pdf.

NABC. (May 23, 2011). "Virent and Fellow NABC CLS Collaborators Make BioFormate Gasoline from Biomass." NABC Highlight. Golden, CO: National Advanced Biofuels Consortium. http://www.nabcprojects.org/pdfs/virent_nabc_make_bioformate_gasoline.pdf.

U.S. Department of Energy (DOE). (2012). “Conversion Technologies for Advanced Biofuels: Preliminary Roadmap \& Workshop Report.” Whitepaper, December 2011 (issued for comment October 2012). https://www.fedconnect.net/fedconnect/?doc=DE-FOA-0000775\&agency=DOE.

"Virent BioForming." Madison, WI: Virent, Inc. http://www.virent.com/technology/bioforming. 